\title{
INTRODUCTION TO THIS ISSUE Dealing with TB in wildlife
}

\section{Introduction}

Tuberculosis (TB) is a disease caused in humans and animals by infection with members of the Mycobacterium tuberculosis complex (MTC). In wild mammals, TB is mostly due to $M$. bovis and closely related mycobacteria such as $M$. caprae. These infections are shared between wildlife, domestic animals and humans, causing zoonotic disease mainly in developing countries, huge economic losses to the livestock industry, as well as conservation concerns worldwide. This Special Issue on TB in wildlife comprises original papers on a diversity of epidemiological situations at the wildlife-domestic animal-human interface over a broad geographical range. This introduction to the Special Issue includes a global perspective and an overview of TB in wildlife and its control, using New Zealand as a case study, with an outlook on forthcoming research.

\section{Global perspective of $\mathrm{TB}$ in wildlife}

M. bovis is a multi-host pathogen that thrives in complex systems at the wildlife-livestock interface. This makes eradication unlikely if the role of all wildlife hosts is not clear enough for relevant reservoirs to be targeted at the same time. The best known wildlife TB reservoirs occur in the British Isles (Eurasian badger, Meles meles), the Iberian Peninsula (Eurasian wild boar, Sus scrofa, red deer, Cervus elaphus, fallow deer, Dama dama), southern Africa (African buffalo, Syncerus caffir, among other hosts), North America (white-tailed deer, Odocoileus virginia$n u s$, in Michigan), and New Zealand (introduced Australian brushtail possum, Trichosurus vulpecula). Several recent reviews have addressed wildlife TB, underlining the need to understand epidemiological complexity, and to use integrated approaches for TB control at the interface $[1,2]$.
However, wildlife TB often occurs outside these better known hotspots. For instance, badger, deer and wild boar TB is increasingly recorded in continental Europe outside the Iberian Peninsula [1]; wild boar and feral pig TB is increasingly recorded in America (e.g. [3, 4]); white-tailed deer TB probably occurs in northern Mexico [5]; and large parts of Africa and Asia still lack a proper assessment of the distribution of wildlife TB. Moreover, some non-bovine domestic and semi-domestic hosts, particularly pigs, goats, camelids or elephants, deserve much more attention regarding their growing role in infection maintenance (e.g. $[3,6,7])$.

In those regions where wildlife MTC infection is regarded as a significant barrier to TB eradication in cattle, research on TB control at the wildlife-livestock interface is making significant progress [4]. For TB eradication in cattle strategies that reduce pathogen transmission between wildlife and domestic animals and between non-bovine livestock and cattle must be developed [8]. This can be achieved by preventative actions, such as host population control through random or selective culling, or through habitat management, and by vaccination. The alternative options of zoning or no-action should also be considered, particularly in view of a cost-benefit assessment. Ideally, tools from several fields should be combined in an integrated control strategy. TB control in New Zealand is an example of such an approach.

\section{Dealing successfully with wildlife TB: the New Zealand case study}

After its first confirmed detection in wildlife in New Zealand in 1967, bovine TB spread to wildlife populations over about $35 \%$ of New Zealand's land area [9]. Through the combined management of infection in livestock and wildlife, only $0 \cdot 2 \%$ of herds were infected in New Zealand at the end of 2011, the first of 
the 3 years required to meet the OIE standard for TB-free country status.

That success was largely due to increasingly effective $\mathrm{TB}$ vector control operations across some eight million hectares [10]. Improvements in the diagnosis and eradication of TB in cattle and deer herds [11] and stringent movement control and animal identification of livestock also played a significant role [12]. Subsequently, the number of infected herds dropped below 60 , a $96 \cdot 5 \%$ decrease from 1714 in 1994 . With the number of cattle and deer herd infections at low levels throughout New Zealand, strategic objectives have changed to address the long-term need of total eradication of TB from wildlife. [13].

The 15-year time-frame of the current strategy sets the platform for eradicating TB from New Zealand. The programme's extensive wild animal control and surveillance schemes initially aim to achieve this across 2.5 million hectares, about one quarter of the 10 million hectares that infected wildlife inhabit. Success with this goal will demonstrate the feasibility of eradicating TB successfully from wild animals throughout the country in the long term and across difficult terrain. New Zealand's prospect of successfully eradicating TB is enhanced by the fact that none of the key wildlife hosts of TB are native animals, and all of them are also controlled to greater or lesser extent as pests of native biodiversity.

The eradication of TB from the complex of wildlife hosts in New Zealand (possums, deer, pigs, ferrets) was long considered impossible. However, theoretical models $[14,15]$ give a better understanding of the roles of the various wildlife vectors of TB [16-18], and improved possum control in extensive forest areas [19] have shown that maintaining very low possum densities across sufficiently large areas for several years will lead to the eradication of TB. Very low possum densities means that the few remaining infected possums will probably die before transmitting the disease to others, leading to a collapse in the disease cycle within their populations and in spillover hosts.

Effective lethal control of possums (the main wildlife maintenance host) remains the cornerstone of TB eradication in New Zealand. Over the last 10 years, progressive improvements in the methodology for large-scale toxin deployment have enabled more efficacious and cost-effective possum control $[19,20]$, backed by the development of new surveillance methods to detect wildlife at low population densities [21, 22].
Wildlife surveying will play an increasingly prominent role in a strategy based on detecting and eradicating TB in wildlife. Information derived from wild animal surveys includes the location of detection devices, traps and animals caught, together with the post mortem and laboratory findings. These data are being used to analyse whether or not TB has truly been eradicated from a given wild animal population and area, an approach referred to as Proof of Freedom [23, 24]. This involves a novel spatial model of wildlife disease-surveillance data using parameters governing home-range size, probability of capture, probability of disease transmission and spatial variation in the probability of infection of reservoir hosts and spillover sentinel wildlife to make inference on the probability of eradication. Such an approach is likely to have broader application in the management of wildlife TB in other countries.

\section{Conclusions and outlook}

We need to understand complexity: the growing evidence on the role of apparently minor or lesser known hosts in TB maintenance shows that an excessive focus on the best known wildlife reservoir hosts can be a risk, due to spill-back from unexpected sources. This is well illustrated in this Special Issue in the paper by Walter et al. regarding Virginia possums (Didelphis virginiana) in Michigan, USA [25]. Targeted research is needed to assess the spill-back risks from less relevant hosts [17]. It would also be prudent to investigate the prevalence of wildlife $\mathrm{TB}$ outside the best known hotspots listed above, particularly where the available information is limited or host populations are changing, so that further disease spread can be prevented.

Based on this understanding, there is an urgent need to monitor TB both in livestock and in wildlife. Only an organized monitoring scheme combining disease indicators with population indicators will enable the outcome of any interventions to be assessed [26]. Finally there is a need for more detailed in-depth research on (integrated) TB control at the wildlifelivestock interface.

Two decades ago, O'Reilly \& Daborn [8] stated in their review on $M$. bovis that:

In countries where there is transmission of infection from endemically infected wildlife populations to cattle or other farmed animals, eradication is not feasible and control measures must be applied indefinitely. 
The example from New Zealand shows that, in fact, eradication of TB in cattle is a realistic goal if TB control in the wildlife reservoir is successfully addressed. Hopefully, other wildlife TB hotspots will follow this example and succeed in this endeavour. This will need strong scientific support, to which the knowledge contained in this Special Issue is a significant contribution.

\section{REFERENCES}

1. Gortázar C, et al. The status of tuberculosis in European wild mammals. Mammal Review 2012; 42: 193-206.

2. Palmer MV, et al. Mycobacterium bovis: a model pathogen at the interface of livestock, wildlife, and humans. Veterinary Medicine International 2012; art. no. 236205.

3. Zumárraga MJ, et al. Understanding the relationship between Mycobacterium bovis spoligotypes from cattle in Latin American countries. Research in Veterinary Science 2013; 94: 9-21.

4. Miller R, Sweeney S. Mycobacterium bovis (bovine tuberculosis) infection in North American wildlife: implications for mitigating risk of further infection in wildlife populations. Epidemiology and Infection 2013. doi:10.1017/S0950268813000976.

5. Medrano C, et al. Zoonotic pathogens among whitetailed deer, Northern Mexico, 2004-2009. Emerging Infectious Diseases 2012; 18: 1372-1374.

6. Di Marco V, et al. Epidemiological significance of the domestic black pig (Sus scrofa) in maintenance of bovine tuberculosis in Sicily. Journal of Clinical Microbiology 2012; 50: 1209-1218.

7. Ong B, et al. Tuberculosis in captive Asian elephants (Elephas maximus) in Peninsular Malaysia. Epidemiology and Infection. Published online: 18 February 2013. doi: $10.1017 / \mathrm{S} 0950268813000265$.

8. O'Reilly LM, Daborn CJ. The epidemiology of Mycobacterium bovis infections in animals and man: a review. Tuberculosis and Lung Disease 1995; 76: 1-46.

9. Coleman JD, Cooke MM. Mycobacterium bovis infection in wildlife in New Zealand. Tuberculosis 2001; 81: 191-202.

10. Hone J. Diminishing returns in bovine tuberculosis (TB) control. Epidemiology and Infection 2013. doi:10.1017/ S0950268813000927.

11. Buddle BM, Livingstone PG, de Lisle GW. Advances in ante-mortem diagnosis of tuberculosis in cattle. New Zealand Veterinary Journal 2009; 57: 173-180.

12. Animal Health Board. Annual report 2011/2012. Wellington, New Zealand.

13. Hutchings S, Hancox N, Livingstone P. Approaches to eradication of tuberculosis from wildlife in New Zealand: a revised pest management strategy. Vetscript 2011; 24: 8-12.

14. Caley P. Bovine tuberculosis in brushtail possums: models, dogma and data. New Zealand Journal of Ecology 2006; 30: 25-34.
15. Ramsey DSL, Efford MG. Management of bovine tuberculosis in brushtail possums in New Zealand: predictions from a spatially explicit, individual-based model. Journal of Applied Ecology 2010; 47: 911-919.

16. Nugent G. Maintenance, spillover and spillback transmission of bovine tuberculosis in multi-host wildlife complexes: a New Zealand case study. Veterinary Microbiology 2011; 151: 34-42.

17. Barron MC, Nugent G, Cross ML. Importance and mitigation of the risk of spillback transmission of Mycobacterium bovis infection for eradication of bovine tuberculosis from wildlife in New Zealand. Epidemiology and Infection 2012. Published online: 5 December 2012. doi:10.1017/S0950268812002683.

18. Yockney I, et al. Comparison of ranging behaviour in a multi-species complex of free-ranging hosts of bovine tuberculosis in relation to their use as disease sentinels. Epidemiology and Infection. Published online: 6 March 2013. doi:10.1017/S0950268813000289.

19. Nugent G, et al. Bait aggregation to reduce cost and toxin use in aerial 1080 baiting of small mammal pests in New Zealand. Pest Management Science 2012; 68: 1374-1379.

20. Nugent G, et al. Effect of prefeeding, sowing rate and sowing pattern on efficacy of aerial 1080 poisoning of small-mammal pests in New Zealand. Wildlife Research 2011; 38: 249-259.

21. Ogilvie SC, et al. Improving techniques for the Waxtag possum (Trichosurus vulpecula) monitoring index. New Zealand Plant Protection 2006; 59: 28-33.

22. Sweetapple P, Nugent G. Chew-track-cards: a multiple species small mammal detection device. New Zealand Journal of Ecology 2011; 35: 153-162.

23. Bosson MAJ, et al. Proving freedom in a disease with multiple host species: an area case study for TB control in New Zealand. Epidémiologie et Santé Animale 2011; 59-60: 95-97.

24. Anderson DP, et al. A novel approach to assess the probability of disease eradication from a wildanimal reservoir host. Epidemiology and Infection. Published online: 23 January 2013. doi:10.1017/ S095026881200310X.

25. Walter D, et al. Surveillance and movements of Virginia opossum (Didelphis virginiana) in the bovine tuberculosis region of Michigan. Epidemiology and Infection. Published online: 26 March 2013. doi:10.1017/ S0950268813000629.

26. Boadella M, et al. Six recommendations for improving monitoring of diseases shared with wildlife: Examples regarding mycobacterial infections in Spain. European Journal of Wildlife Research 2011; 57: 697-706.

C. GORTAZAR ${ }^{1}$ AND P. COWAN ${ }^{2}$

${ }^{1}$ SaBio IREC (CSIC-UCLM-JCCM),

Ronda de Toledo s.n. 13005 Ciudad Real, Spain

${ }^{2}$ Landcare Research, PO Box 40, Lincoln 7640, New Zealand

(Email: Christian.Gortazar@uclm.es) [C.G.]

(Email: cowanp@landcareresearch.co.nz) [P.C.] 